\title{
Formação de Professores e Método de Ensino para Crianças Surdas ${ }^{1}$ Teacher Training and Teaching Method For DeAF Children
}

\author{
Ednalva Gutierrez RODRIGUES ${ }^{2}$ \\ Cláudia Maria Mendes GONTIJO 3 \\ Rogério DRAGO 4
}

\begin{abstract}
RESUMO: Este artigo discute a proposta de formação de professores e os embasamentos do método adotado para ensinar crianças surdas, no período de 1951 a 1961, quando Ana Rímoli de Faria Dória esteve na direção do Instituto Nacional de Educação de Surdos (INES). Com base na concepçáo de história de Marc Bloch, elegeu-se como metodologia a pesquisa histórica. Foram analisados discursos registrados nos Anais da $1^{\text {a }}$ Conferência Nacional de Professores de Surdos, realizado no INES, em 1959, e textos auxiliares. Os resultados apontam que a concepção de educação, fundamentada na correção da deficiência, dialogou com concepçóes teóricas que circulavam naquela época, influenciando a formação de professores, pois estes deveriam ensinar as crianças surdas a oralização e a leitura labial, conforme princípios do Método Oral Puro, adotado em todo o território nacional.
\end{abstract}

PALAVRAS-CHAVE: Educação de crianças surdas. Formação de professores. Método de ensino.

ABSTRACT: This paper discusses the proposal of teacher training and the foundations of the method adopted to teach deaf children, from 1951 to 1961, in which Ana Rímoli de Faria Dória was the director of the National Institute for Education of the Deaf (INES). Based on Marc Bloch's conception of history, the historical research was chosen as methodology. Speeches recorded in the Annals of the 1st National Conference of Teachers of Deaf Learners, held at INES, in 1959, and supporting texts were analyzed. The results point out that the conception of education, based on the correction of the disability, had a dialog with theoretical conceptions spread at that time, influencing teacher training, since they should teach oralization and lip reading to deaf children, according to the principles of the Pure Oral Method adopted throughout the national territory.

KEYWORDS: Education of deaf children. Teacher training. Teaching method.

\section{ConsideraÇóEs INICIAIS}

Este artigo é um desdobramento de uma pesquisa que investigou a história da alfabetização de surdos no Espírito Santo entre as décadas de 1950 e 1970, como parte de uma política nacional de descentralizaçáo na educação de surdos, assumida pelo Instituto Nacional de Educação de Surdos (INES), que culminou com a implantação de salas ou escolas especiais em vários Estados do Brasil. Neste texto, discutimos, no período em que Ana Rímoli de Faria Dória esteve na direçáo desse Instituto (1951 a 1961), a proposta de formaçáo de professores e os embasamentos do método adotado para ensinar crianças surdas. A formação de professores foi, na nossa análise, um dos pilares do projeto da descentralização da educação de surdos e também serviu de base para a organização pedagógica das classes que foram criadas em vários Estados brasileiros.

Como referencial teórico, tomamos a concepção de Marc Bloch (2001) para compreender a História não como cronologia, pois a História não pode ser reduzida a uma en-

\footnotetext{
${ }^{1}$ http://dx.doi.org/10.1590/s1413-65382620000100009

${ }^{2}$ Departamento de Linguagens, Cultura e Educação. Universidade Federal do Espírito Santo. Vitória/Espirito Santo/Brasil. Email: nalvaguti@hotmail.com. ORCID: https://orcid.org/0000-0002-7726-9994

${ }^{3}$ Departamento de Linguagens, Cultura e Educação. Universidade Federal do Espírito Santo. Vitória/Espirito Santo/Brasil. Email: clammgont@gmail.com. ORCID: https://orcid.org/0000-0003-2365-937X

${ }^{4}$ Departamento Teorias do Ensino e Práticas Educacionais. Universidade Federal do Espírito Santo. Vitória/Espirito Santo/Brasil. Email: rogerio.drago@gmail.com. ORCID: https://orcid.org/0000-0001-8998-6299
} 
ciclopédia com a narrativa de grandes acontecimentos, dos feitos dos grandes heróis e das mudanças provocadas por eles. Ao historiador cumpre a tarefa de estudar e compreender os seres humanos, principais agentes da História, seja qual for a sua condição social, econômica ou política, inserida no contexto social de sua época. Como as ideias e os pensamentos dos humanos são dinâmicos, a História não pode ser imutável e fixa, já que se constitui a partir da ação dos indivíduos no tempo, das suas expectativas, certezas e incertezas e das concepçóes da época em que atuaram.

Ao reconhecer a possibilidade de contrapalavra ao discurso oficial e a recusa por uma lei incontestável, Bloch (2001) não só reconhece o valor dos documentos oficiais, mas também agrega novos valores considerados não oficiais e que ficaram marginalizados pelos historiadores mais tradicionais, pois: "A diversidade dos testemunhos históricos é quase infinita. Tudo que o homem diz ou escreve, tudo que fabrica, tudo que toca pode e deve informar sobre ele" (p. 79). Essa afirmação leva-nos a concluir que a verdade não está cristalizada no documento, mas nos sentidos elaborados a partir de perguntas do historiador, porque "os textos ou os documentos arqueológicos, mesmo os aparentemente mais claros e mais complacentes, não falam senão quando sabemos interrogá-los" (Bloch, 2001, p. 79).

Assim, para compreender a atuação dos sujeitos que participaram da construção da proposta de formação de professores de crianças surdas, adotamos, como opção metodológica, a pesquisa histórica pelo fato de o pesquisador poder analisar documentos e, desse modo, questioná-los a fim de buscar entender as posiçóes dos sujeitos que os produziram. Nessa direção, o corpus analisado neste artigo é constituído por discursos registrados nos Anais da $1^{\text {a }}$ Conferência Nacional de Professores de Surdos, realizada no INES, em 1959. Interessam-nos, mais de perto, a palestra proferida por Ana Rímoli, diretora e representante oficial da Campanha para Educação do Surdo Brasileiro, em que destaca a formação de professores e seus fundamentos, assim como o método adotado para a educação dos surdos pelo INES. Cotejamos o discurso da diretora com publicaçóes de sua autoria que versam sobre a educação da criança surda e também sobre o currículo adotado no Curso Normal nos anos de 1951, 1952 e 1953, referentes à primeira turma, que nos dá uma ideia das bases linguísticas e psicológicas que fundamentaram a educação de surdos.

No Brasil, conforme encontrados por meio de buscas realizadas no portal da Coordenação de Aperfeiçoamento de Pessoal de Nível Superior (Capes) em revistas científicas, foram realizados estudos que se dedicaram a pesquisar a educação de surdos em uma perspectiva historiográfica. Os autores que utilizaram esses estudos adotaram, como opçóes metodológicas, a pesquisa documental ou as narrativas.

Soares (1996), ao investigar as narrativas apresentadas para a história da educação de surdos na produção bibliográfica e acadêmica, a partir dos anos de 1990, afirma que, na gestão de Ana Rímoli de Faria Dória (1951 a 1961), os projetos que se efetivaram foram idealizados ainda na administração dos seus antecessores, dentre eles, o de formação de professores, que tinha como escopo a descentralização da educação de surdos e o oralismo como proposta metodológica e culminou com a Campanha de Educação do Surdo Brasileiro.

Souza (2007), Schimitt (2008) e Neves (2011) apresentaram, respectivamente, os primeiros indícios da implantação dessa política de descentralização, realizada pelo INES, na 
década de 1950, em Aracaju, Sergipe (SE); Santa Catarina (SC) e Caxias do Sul, Rio Grande do Sul (RS). Essas pesquisas confirmaram a influência do Instituto como órgão gestor de políticas públicas na formação das professoras, lugar assumido até os dias de hoje. Os currículos mobilizados nas classes de surdos apontam para a redução dos conhecimentos a serem aprendidos com foco no ensino da língua oral.

$\mathrm{Na}$ mesma direção, Cardoso e Herold Júnior (2016) investigaram a educação de surdos na década de 1950. Utilizaram, como fonte primária, as obras Introdução à didática da fala (1959), Compêndio de educação da criança surdo-muda (1958) e Manual de educação da criança surda (1961), publicadas por Ana Rímoli, visto que, nessa época, ao assumir a direção do INES, ela promoveu importantes mudanças, dentre elas, às relativas à formação de professores especialistas.

Os estudos evidenciaram que a principal preocupação de Ana Rímoli era ensinar as crianças surdas a falar, pois, sem essa capacidade, não haveria a comunicação e, consequentemente, a criança surda teria dificuldades em se desenvolver de forma saudável e segura. Por isso, de acordo com a diretora do Instituto, para o sucesso da educação de surdos,

era de essencial importância a formação do professor. Ela defendia que os professores deveriam dominar questóes teórico-práticas da psicopedagogia especial, ter um olhar multifacetado em relação aos alunos, levando em conta suas especificidades para a adaptação do ensino. (Cardoso \& Herold Júnior, 2016, p. 11).

Para fundamentar o ensino e a formação de professores, conforme assinalam Cardoso e Herold Júnior (2016), Ana Rímoli de Faria Dória iniciou um intenso diálogo com autores oralistas, dentre eles, Alexander Graham Bell, Martha E. Bruhn, Herr Julius Müller-Walle, Edward B. Nitchie e Cora Elsie Kinzi. Ela definiu o método oral como o mais indicado no ensino das crianças surdas. Nesse cenário, além das bases linguísticas, alinhadas à concepção oralista que circulava em outros países, Ana Rímoli também estabeleceu um amplo diálogo com autores que estudavam aspectos psicológicos da educação, como veremos a seguir.

\section{FORMAÇÃ́o DE PROFESSORES}

A década de 1950 foi fundamental para a descentralização na educação de surdos. Juntamente ao projeto de modernização do Brasil, implementado pelo Governo Federal, com o objetivo de alfabetizar o surdo, o INES empreendeu um grande esforço com vistas à formação de professores para atuar nos Estados brasileiros. Duas ações, a Campanha para Educação do Surdo Brasileiro e o Curso Normal para Professores de Surdos, foram fundamentais para inserir a pessoa surda na vida econômica e social do país.

A Campanha para a Educação do Surdo Brasileiro, ocorrida em 1957, pode ser situada no bojo das medidas educacionais que começam no Governo Juscelino Kubistchek (19561961), cuja finalidade foi a "erradicação" do analfabetismo, mas, sobretudo, a formação de mão de obra para atuar na indústria, considerando o fato de esse governo ter adotado, em termos econômicos, uma política denominada por Fausto (2010) de nacional-desenvolvimentista, entendida como a combinação do "Estado, a empresa privada nacional e o capital estrangeiro para promover o desenvolvimento, com ênfase na industrialização” (p. 427). 
Nesse contexto, caberia ao INES a tarefa de ampliar a alfabetização aos surdos brasileiros, por meio da formação de professores especializados e, portanto, "ampliação da rede educativa e assistencial para tais crianças, iniciando a penetração no interior do País, através da necessária descentralização técnico-administrativa” (Dória, 1959). Assim, o Governo Federal realizou esse projeto por meio de duas ações básicas: a descentralização administrativa, criando novas salas para surdos em alguns Estados brasileiros; e a formação de professores, alicerçada em bases científicas atuais.

Segundo relatório apresentado na $1^{\text {a }}$ Conferência Nacional de Professores de Surdos, realizada no INES, em 1959, nesse ano, de um total de 84 unidades escolares que já ministravam educação aos surdos, espalhadas por 12 Estados da Federação, 61 eram providas por professores formados pelo INES. Por meio da Campanha para Educação do Surdo Brasileiro, o Instituto já havia firmado convênio com 31 unidades escolares. Outras sete unidades da Federação e três escolas particulares aguardavam para serem incluídas no convênio.

Com esses dados, Ana Rímoli, no discurso proferido na Conferência, buscou demonstrar para o público presente os resultados positivos obtidos com a campanha ainda em curso e a formação de professores, iniciada em 1951, por meio do Curso Normal, e ampliada em 1957, com o Curso de Especialização. Rocha (2009) ponderou, em sua pesquisa, que essas medidas se alinharam com o ideário escolanovista, porque,

com a presença de Anísio Teixeira à frente do Instituto Nacional de Estudos Pedagógicos (Inep), a idéia de reconstruçáo educacional do país, em bases científicas, ganha corpo, assim como a prioridade no desenvolvimento de açóes ligadas à formação docente. (p. 72).

Seguindo o modelo implantado por Anísio Teixeira, em 1954, que organizou centros de treinamento e de capacitação de profissionais para o ensino primário e normal, o Instituto assumiria a função de ser o Centro Nacional de Referência, tendo outros cinco Centros Regionais distribuídos pelo Brasil, descentralizando o ensino emendativo (atual ensino especial) cujo objetivo era reabilitar pessoas com deficiências mentais para, posteriormente, inseri-las na escola regular (voltaremos a tratar desse assunto), possibilitando "a criação de classes especiais em escolas públicas, a criação de escolas especializadas e, também, a concessão de bolsas de estudos para que os alunos surdos pudessem estudar em escolas particulares" (Rocha, 2009, p. 85).

Rocha (2010, p. 80) observou ainda que a criação do Curso Normal, para fins específicos de formação de professores de surdos, foi a primeira iniciativa com vistas à "descentralização, regionalização e interiorização do ensino para surdos em âmbito nacional”. A instalação da campanha foi a culminância do projeto. Além do apoio administrativo com fins de descentralização, coube à Campanha para Educação do Surdo Brasileiro promover todos os meios para o apoio e a difusão de iniciativas necessárias à educação e à assistência dos deficientes da audição.

O currículo do Curso Normal, com duração de três anos, era composto por uma parte geral, comum ao Curso Normal do Instituto de Educação do Rio de Janeiro, e outra específica, direcionada à educação de surdos e fundamentada nas concepçóes biológicas e psicológicas da surdez, com as seguintes disciplinas: Português e Linguagem Fonética, Histologia, Física, Ensino Emendativo, Fonação, Didática Especial e Patologia da Audição. No ano de 1952, o INES convidou a professora argentina Angela Liza de Brienza para ministrar aulas de Fonética 
e Didática Especial, o que, de certa forma, contribuiu para demarcar o método adotado por esse instituto no período.

Além do Curso Normal, como mencionado, teve início, em 1957, o Curso de Especialização, de dois anos, com a finalidade de acelerar a descentralização do ensino emendativo no Brasil. Para tal, recebeu "professores primários, originários das várias Unidades da Federação. Sua primordial finalidade consiste em habilitar professores já formados e com prática de dois anos, pelo menos, de magistério comum, na didática especial de surdo" (Dória,1959). No currículo, apresentado por Ana Rímoli, relativo às $1^{\text {a }}$ e $2^{a}$ séries, há predominância de disciplinas sobre a aquisiçáo da fala, conforme mostra o Quadro 1.

\section{$1^{a}$ série}

Psicologia da linguagem

História da educação dos deficientes da audição e da fala

Didática do ensino primário elementar, complementar e supletivo aos deficientes da audição e da fala

O treinamento da leitura da fala

O ensino da fala

$\mathrm{O}$ treinamento auditivo

Acústica e física do som

Anatomia e fisiologia da audição e da fala

Sociologia

Fonética para os deficientes da audição e da fala

Didática do desenho e Artes aplicadas

Ginástica coreográfica - recreação e jogos

Canto orfeônico

\section{$2^{a}$ série}

Psicometria e demais mensuraçōes

Princípios metodológicos da pesquisa

Prática do ensino primário elementar, complementar e supletivo aos deficientes da audição e da fala

Patologia da audição e da fala

Logopedia

Educação comparada

Noções de direito aplicada

Ginástica coreográfica - recreação e jogos

Canto orfeônico

Disciplinas optativas: Higiene auditiva e visual e Inglês (atualizado)

Quadro 1. Currículo do Curso de Especialização para Professores

Fonte: Adaptado pelos autores do acervo do INES.

Se, por um lado, Ana Rímoli defendia uma formação para os professores fundamentada em bases científicas; por outro, destacava a função remidora da educação, a de salvar as crianças surdas do seu infortúnio era uma missão a ser cumprida, pois, em sua perspectiva: "O 
amor é que será o 'abre-te sésamo’ milagroso, através do qual o aluno e professor se entenderão diminuindo vagarosamente, suave e progressivamente, a distância que os separa" (Dória, 1959). Luckesi (1994) considera que a essa visão está subjacente a uma concepção redentora de educação fortemente vinculada à ideia de que, por meio da educação, pessoas excluídas poderiam ser inseridas nos processos culturais. Nesse sentido, ao professor de crianças surdas, caberia salvá-las da ignorância, da miséria e da marginalidade, por meio da restituição do que lhes faltava: a fala.

Para exemplificar sua afirmação quanto à finalidade da educação, Ana Rímoli faz uma vinculação entre Teologia e Pedagogia, ao relacionar a redenção dos pecadores, por meio de Jesus Cristo, com a redenção dos ignorantes, por meio da educação, pois, assim como os pecadores podem ser salvos e viver em harmonia com Deus, os marginalizados poderiam ser instruídos e viver em harmonia no seio da sociedade. Para confirmar essa relação, assinalou que os professores se dedicavam "a um dos mais belos empreendimentos que Cristo legou aos homens, na face da terra” (Dória, 1959).

Desse modo, o discurso de Ana Rímoli foi permeado pelo uso de termos ligados a sentimentos, como entusiasmo, carinho, compreensão, paciência, perseverança, força interior, confiança, renúncia e serviço. Nesse sentido, a formação que ajudaria os professores a ensinar crianças surdas deveria estar fundada em bases científicas, mas também precisaria prepará-los para uma missão que exigiria deles sentimentos nobres para conduzir sua missão remidora.

Na referida conferência, a então diretora da instituição, Ana Rímoli, em seu discurso, acrescentou: "Qualquer professor tem o dever de conhecer e ensinar o Português, nosso idioma pátrio, à criança deficiente de audição com maior profundidade e amplitude” (Dória, 1959). Nesse sentido, inferimos que a diretora vislumbrava que a formação para atuar com crianças surdas poderia ser estendida para todos os docentes, antevendo, inclusive, a sua inclusão na escola regular.

\section{OrganizaÇáo E embasamentos do MÉTodo de ENSINo}

Ana Rímoli também defendeu, em seu discurso, o tipo de ensino adotado pelo INES, situando-o no campo da Pedagogia Emendativa. Com relação a essa pedagogia, Milton Acácio de Araújo, professor de História do Ensino Emendativo e palestrante na referida conferência, propôs que o evento ratificasse a criação de normas de educação e ensino adequadas e com alcance "a todos os estabelecimentos de ensino emendativo, tomado na acepção larga do termo, a fim de beneficiar a todos os portadores de qualquer deficiência física e sensorial ou desajustamento social" (Araújo, 1959).

Para justificar a necessidade de maior regulamentação nessa área, o professor apresentou o quantitativo de deficientes inscritos nas características citadas, carentes de assistência e educação, portanto alvo da Pedagogia Emendativa. Dentre eles, surdos totais, parciais e falantes, 500.000; surdos que não falam, 80.000; deficientes da linguagem, 50.000; e surdos-mudos cegos, 400. Também as prostitutas, os mendigos, os encarcerados; enfim, todos os excluídos socialmente poderiam ser assistidos pelos princípios do ensino emendativo. O objetivo desse tipo de ensino seria restituir à normalidade os anormais ou aqueles com algum desvio, por meio da educação. 
Assim, a criança surda é vista como anormal, em comparação às outras crianças consideradas "normais", por não terem o "defeito" da surdez e serem saudáveis. Ainda em seu discurso, Araújo (1959) afirmou: "O problema médico-pedagógico dos deficientes físicos e sensoriais hoje é encarado seriamente por todos os países que compreendem a necessidade de recuperá-los, tendo em vista a correção psicológica e a readaptação ao trabalho". Nessa direção, o propósito central da educação de surdos - a sua readaptação ao trabalho -alinhava-se à política nacional-desenvolvimentista adotada pelo Governo Federal.

Em seu discurso, Ana Rímoli apontou, ainda, a necessidade de tratamento especial para cada caso, de acordo com a "anormalidade". As finalidades do tratamento seriam, além de formação de mão de obra produtiva, a formação moral e religiosa e para a vida social, como mostra o excerto a seguir:

aplicando o tratamento especial indicado em cada caso, sob o ponto de vista educativo para atingir a formaçáo moral e religiosa e a capacidade para o trabalho e para a vida social dos rapazes e moças. Procuram vencer as dificuldades psíquicas, as inibiçóes e os transtornos de toda natureza, decorrentes do retardo mental, da falta de visão ou da audição e fonação. (Dória,1959).

Desse modo, o ensino emendativo, na visão de Ana Rímoli, direcionado a pessoas consideradas com problemas e desvios, deveria ser especializado, com estratégias específicas para cada caso. Com base nessas ideias, afirmou que o professor deveria conhecer as potencialidades de seus alunos, com vistas à "socorrer essas criaturas que não podem dispensar o auxílio de um professor especializado na sua trajetória, trazendo-as assim ao convívio normal, na sociedade a que pertencem e eliminando o raquitismo de sua personalidade e de sua mente" (Dória, 1959). Assim sendo, quais seriam as bases para essa especialização do professor?

Segundo Ana Rímoli, na educação moderna, o conteúdo ensinado na escola comum, organizado em disciplinas, diferenciava-se do modelo tradicional, pois parte dos "interesses, atitudes, discernimento, controle intelectual de seu meio, através de atitudes e vivas experiências" (Dória, 1959). Assim, ao professor de crianças surdas, além de levar em conta esses princípios, caberia a tarefa de ensiná-las a falar uma língua que elas jamais ouviram e, paralelamente, desenvolver a sua inteligência. Nesse sentido, esse professor deveria ter competências no campo da linguagem e, como mencionado, ter um caráter idealista, dedicado e missionário, para mobilizar os mais modernos métodos de ensino da fala e preparar essa criança para a vida plena e autônoma.

A escola especializada, na opinião de Ana Rímoli, seria a escola das crianças surdas; e a escola comum, a das crianças ouvintes. Sobre a criança surda, considerou que o maior desafio dos docentes era o grau da surdez, pois, de acordo com sua visão,

quanto maior a deficiência, maiores as dificuldades em relação à linguagem. A razão é óbvia; a criança aprende a falar por imitaçáo; deficiente da audiçáo, náo podendo ouvir ou ouvindo mal a voz humana, não terá padróes de linguagem a imitar. (Dória, 1959).

Por isso, Ana Rímoli defendeu que a linguagem oral não poderia ser aprendida de formal natural, já que é fruto de uma capacidade fonética, inexistente para a criança surda. Em seu livro intitulado Compêndio de educaçâo da criança surdo-muda, usado como referência para a formação de professores, analisou minuciosamente a estrutura mental de uma criança que, 
por não ouvir, não poderia ter acesso ao mundo simbólico, pois, mesmo compreendendo os fatos, pela visão ou pela imitação das ações das pessoas que vivem em seu entorno, não pensava logicamente, porque "o pensamento lógico depende de novas disposiçóes das 'unidades de pensamento', que são as nossas palavras” (Dória, 1958, p. 37). Sem isso, conforme sua opiniāo, o pensamento da criança surda, não educada, seria sempre generalista, impreciso e vago. "As crianças sem palavras são também crianças sem pensamento real” (Dória, 1958, p. 37).

Em outra publicação, intitulada Manual da educação da criança surda (1961), Ana Rímoli aprofundou a sua concepção de linguagem, ao afirmar que linguagem e fala se diferenciam na medida em que a linguagem é definida como a ideia que temos sobre as coisas que existem; desse modo, a ideia é o que temos sobre o que vamos dizer, e a fala é o meio sonoro e acústico que utilizamos para transmitir essa ideia, por meio de palavras. Com essa distinção, uma criança que ouve não terá a linguagem comprometida, pois as "sensaçóes auditivas, recebidas com muita frequência, vão preparando a mente da criança para a repetição, para a reprodução dos sons que ouve, pela sua capacidade inata de imitação" (Dória, 1961, p. 52). Vemos, assim, que o desenvolvimento de qualquer indivíduo se dá por meio deste tripé: audição, pensamento e fala.

Dessa forma, Ana Rímoli advogou para as crianças surdas o mesmo direito de desenvolver o pensamento e a expressão, por meio da aprendizagem especializada da linguagem oral, com "exercícios adequados, sistematicamente preparados, para a /obtenção e desenvolvimento da fala” (Dória, 1961, p. 52). Nessa perspectiva, a aprendizagem das palavras não se constitui em um processo puramente fisiológico e fonético.

Ao dialogar com linguistas estruturalistas norte-americanos, ${ }^{5}$ que também concebiam a linguagem em uma perspectiva cultural, Dória (1961) afirmou que o desenvolvimento do pensamento por meio da aprendizagem de novas palavras deveria ser um processo com sentido e partir das experiências das crianças, porque: "A linguagem é um ato fisiológico no qual participam muitos órgãos do corpo humano e que pressupóe a atividade voluntária do espírito; é um ato social que responde a uma necessidade de comunicação entre os homens, afirma J. Vendryes” (p. 56). Nessa direção, aprender a falar palavras deveria integrar um processo conjunto entre a necessidade de aprender os símbolos e a necessidade de comunicação, tornando esse processo mais significativo.

Influenciada por Sapir (1954), Ana Rímoli afirma, com relação à fala, que o "[...] processo de desenvolvimento náo se efetua por métodos mecânicos, pois o objetivo e a compreensão do sentido muito auxiliam no processo do falar bem" (Dória, 1961, p. 54). Assim, embora a criança esteja biologicamente apta a falar e para isso use o aparelho fonador, a aprendizagem de uma língua é um processo cultural que deve fazer sentido. Para exemplificar, ela diz que, conforme Sapir (1954),

\footnotetext{
${ }^{5}$ Edward Sapir, antropólogo e linguista. "Edward Sapir foi, sem dúvida, um dos estudiosos que mais se destacou no cenário linguístico dos Estados Unidos; ele compunha, juntamente com Franz Boas, Bloomfield e outros, o movimento do estruturalismo norte-americano" (Teixeira \& Mota, 2011, p. 6); “J. Vendryes, representante da linguística afectiva, Hugo Schuchardt, representante da Escola de 'palavras e coisas', Benedetto Croce, Karl Vossler e outros que reconhecem como relevante a ligação existente entre o mundo interior, psicológico, das pessoas e a língua que o reproduz, sendo a linguagem comparada a um espelho que reflecte a essência do homem e sendo o estilo caracterizado como uma expressão individual do ideal estético do homem”. (Svodobov, 2008, p. 58).
} 
a palavra 'casa', não é um fato linguístico se apenas virmos nela o efeito acústico produzido pelas vogais e consoantes que o constituem, pronunciadas numa certa ordem; nem os processos motores e as sensaçôes táteis resultantes da articulaçáo do vocábulo, nem a percepção auditiva dessa articulação por parte do ouvinte, nem a percepção visual do vocábulo na página manuscrita ou impressa, nem os processos motores e as sensação táteis que fazem parte do ato de escrever o vocábulo, nem a memória de uma dessas ou de todas as experiências. Somente quando essas e outras experiências se associarem a imagem de uma casa, é que começam a tomar a feição de símbolo, de palavra do elemento linguístico. (Dória, 1961, p. 54).

Nesse contexto, para a criança surda que não ouve, aprender a "usar os símbolos verbais, associar sons e 'figuras de palavras' a ideias [...]” (Dória, 1959) assumiria um lugar central em todo o processo de escolarização, priorizando, para isso, a repetição e a memorização de palavras com sentido completo, pois o processo de ensino esboçado por ela "é um processo de 'imitação', pelo qual a criança aprende a falar imitando, adquirindo habilidades mecânicas de linguagem 'de fora para dentro' e não de 'dentro para fora'” (Dória, 1961, p. 226). Essa premissa será o fundamento do método utilizado na oralização das crianças surdas.

Em seu discurso, Ana Rímoli evidenciou que, para desenvolver a dimensão psicológica das crianças surdas e, portanto, para reforçar a sua estrutura mental de modo que possam ampliar seus conhecimentos, elas teriam que aprender a linguagem em seu duplo aspecto: "através da forma motora das palavras nos lábios, na face de quem fala, e expressa verbalmente através de meticulosa e trabalhada construção dos fonemas de nosso idioma”. Ana Rímoli concluiu dizendo que "nada pode ser ensinado sem que seja falado pelo professor, isto é através da linguagem” (Dória, 1959).

Logo, o professor das crianças surdas deveria ensiná-las a articular a linguagem ou falar as palavras e entendê-las na face de quem fala, ou aprender a ler a fala, conforme princípios do Método Oral Puro. Analisando a importância da oralização para a educação da criança surda, Dória (1958) assinala em seu livro:

A educaçáo (dos que nasceram surdos ou ensurdecidos antes de terem aprendido a falar) ou a reeducação (dos que ensurdeceram depois de terem aprendido a falar) consiste em promover o desenvolvimento integral das possibilidades máximas da criança surda, para sua adaptação suave e completa à sociedade em que vive, através dos processos de leitura oral ou leitura labial, como dizem outros e do ensino da fala, fatores básicos do chamado método oral, na linguagem da pedagogia emendativa. (p. 72).

Assim sendo, o Curso Normal para professores de surdos deveria fornecer elementos que subsidiassem as professoras na oralização das crianças surdas, para que elas pudessem aprender a falar a língua oficial do país, confirmando, dessa maneira, a concepção de linguagem atrelada à vocalização. Sem a fala, não há linguagem e sem linguagem a criança surda não estará preparada "para atender à expressão oro-facial e exprimir seus próprios pensamentos e sentimentos” (Dória, 1958, p. 18). Em termos pedagógicos e sociais, a escolarização da criança surda só seria possível com a aprendizagem inicial da linguagem oral, pois:

Linguagem traduz pensamento; para haver linguagem é preciso que haja pensamento; ora, é sabido que a mente só trabalha ou age em termos de situaçáo problemática. É preciso estimulá-la pela curiosidade para que o pensamento se dê e os processos mentais entrem em atividade. 
Nisto se fundamenta o princípio objetivo de toda a criança, em geral. Que não se dizer então da criança surda?. (Dória, 1958, p. 108).

A concepção de linguagem como expressão do pensamento, conforme assinala Bakhtin (1992), postula que o psiquismo individual constitui o fundamento da língua, esta última vista como um sistema estável, pronto para ser aprendido. Por isso, se tomarmos a história da alfabetização das crianças ouvintes, veremos que elas precisavam se apropriar da língua para se expressarem bem. No período preparatório para a alfabetização, por exemplo, as crianças ouvintes também eram treinadas a produzir adequadamente unidades menores da língua oral, como sílabas e fonemas, por meio de atividades de discriminação auditiva.

Nesse sentido, era necessário, como requisito para a alfabetização, aprender a distinguir sons. É claro que a falta de audição trazia outras implicaçóes, negativas e positivas, do ponto de vista dos que buscavam ensinar a linguagem correta, erudita. As crianças surdas não podiam ouvir esses segmentos sonoros, mas poderiam aprender a pronunciá-los "corretamente", pois não eram usuárias de uma língua que precisava de correçóes, do ponto de vista da linguística tradicional. Nesse quadro, ao professor especializado caberia conhecer todos os fundamentos da linguagem, a saber, os psicológicos, sociológicos, fonéticos, linguísticos, semânticos, fisiológicos, neurológicos, constituindo-se como verdadeiros instrumentos no ensino ao aluno deficiente.

Ana Rímoli defendeu um ensino que priorizasse a educação sensitiva, o uso dos sentidos. Nesse caso, o mais indicado seria o método globalizado, em que o ensino parte de um plano geral para o específico. O ensino aconteceria de forma interdisciplinar, de acordo com as experiências e interesses das crianças, rompendo com a clássica divisão entre as matérias, pois o objetivo principal não era ensinar, "português, ciência, número, etc., mas pretende desenvolver no educando interesses, atitudes, discernimento, controle intelectual de seu meio, através de atitudes e vivas experiências" (Dória, 1959).

Esse pressuposto também seria adotado no ensino da língua oral, já que a criança, ao pronunciar palavras, ela o faz com sentido completo. Então, o ensino da língua oral deveria ser contextualizado e partir de frases ou palavras. Segundo Ana Rímoli: "Esse ponto de vista coincide com a concepção atual dos linguistas a propósito do elemento linguístico ser a frase e não a palavra, e com a observação dos psicólogos da infância, a respeito do emprego da palavra com um sentido perfeito" (Dória, 1959).

Fornecendo exemplos e sugestóes, em forma de roteiro de atividades e reafirmando a necessidade de o ensino para crianças surdas partir de palavras ou frases com sentido, o exemplo, a seguir, sobre o ensino da leitura da fala, é significativo, pois nos dá uma visão dos objetivos que as crianças surdas deveriam atingir em sua escolarização:

Roteiro de vocabulário mínimo para a série inicial

1. Cumprimentos: bom dia, boa tarde, boa noite, até amanhã, passe bem, até logo e adeus.

2. Ensino de números: (1 a 24) das horas, das datas e combinação de todos.

3. Dinheiro: noção, valor e aplicação em compras, na farmácia, no açougue, no armazém, na padaria, na confeitaria e na quitanda.

Noções mínimas a compreender:

a) Farmácia: algodão, álcool, sabonete, remédios, injeção, xarope, comprimido [...]. 
4. Ordens simples: faça, ande, pule, corra, deite-se, levante-se, suba, desça, olhe, venha, vamos, abra, feche, diga, ria, veja, escreva e leia, apague.

5. Ensino do ritmo das palavras e das modificaçóes que ocorrem nos movimentos da fala, com variação de posiçóes da face e do corpo (utilizando a matéria aprendida).

6. Prática de histórias

(1) Empregando frases curtas sobre assunto determinado

(2) Modificando vocabulário

(3) Usando palavras simples

(4) Fazendo perguntas

7. Início de prática analítica dos elementos fonéticos: vogais.

8. Comparação do tempo da duraçáo das vogais.

9. Prática analítica dos elementos fonéticos: ditongos e consoantes, atentando para a visibilidade dos fonemas do p-b-m; do f e v; de d e c; de s e z; de z e j; do c e g; etc. Empregar listas de palavras para análise e observação deste ponto. (Dória, 1961, p. 137-139).

À medida que a criança fosse se desenvolvendo nessas atividades de ampliação do léxico e análise fonética, o professor deveria propor atividades mais complexas com histórias mais longas, narraçōes etc. A repetição era um princípio a ser observado para que a criança não se esquecesse de todas as palavras aprendidas e memorizasse os movimentos da face do seu interlocutor. O desenho ou as imagens visuais deveriam ser amplamente utilizados para que a criança pudesse construir a imagem mental do objeto a ser aprendido. Os cartazes ou cartóes de imagens deveriam conter apenas a imagem do objeto para que o fundo náo confundisse a criança na associação da palavra ao desenho. "Um fundo qualquer nas figuras confunde e destrói a ideia clara que se está tentando construir” (Dória, 1958, p. 84). Finalmente, o livro propóe uma série de jogos/brincadeiras com a finalidade de auxiliar no ensino da leitura da fala, na medida em que a criança aprendia brincando, além de fixar os conteúdos já aprendidos. Somente após ter desenvolvido processos mentais de compreensão das palavras é que ela poderia dar o passo seguinte, o aprendizado da fala, constituindo-se no ponto central desse aprendizado.

O êxito na tarefa de ensinar a criança surda a falar só seria possível se um conjunto de fatores fosse observado, pois falar não implicava apenas emitir sons. O professor deveria observar "a respiração, a articulação, a emissão, a entonação ou tonalidade, a intensidade, o timbre da voz e a música da frase" (Dória, 1958, p. 108). Além disso, a criança também deveria ser inserida em atividades contextualizadas, inicialmente pelo aprendizado de palavras fáceis. Esse era um processo mecânico e de repetição, pois a criança só avançaria na ampliação do léxico, se pronunciasse a palavra corretamente.

Apenas nesse momento o foco do ensino passaria do contexto mais amplo, a palavra, para o contexto mais específico, os fonemas. As palavras corretas fariam parte de um caderno que se tornaria um material a ser consultado e revisitado com fins mnemônicos. Outro material sugerido eram os cartazes com desenhos, palavras e letras de imprensa com o objetivo de associar a palavra falada à sua forma escrita. A escolha das palavras a serem ensinadas deveria seguir o interesse das crianças, a partir dos contextos familiares ou escolares. Ao serem apresentadas, náo deveriam estar sozinhas, mas inseridas em sentenças, de acordo com as características do Método Intuitivo, conforme o texto abaixo:

Isto é uma bola, Paulo

É uma bola grande. 
Ela rola.

Veja, a bola rola assim (mostrar).

Agora, jogue você a bola, Paulo.

Jogue a bola para mim.

Oh! você jogou a bola. (Dória, 1958, p. 231).

Nesse exemplo, a palavra "bola" deveria ser repetida várias vezes, até que a criança a memorizasse. Esse trabalho sistematizado tinha por finalidade dar condiçóes para que a criança ampliasse o léxico de palavras novas, sem esquecer as aprendidas. Mobilizando o conceito de maturação, Ana Rímoli argumentou que, até que a criança chegue ao nível ideal para falar, ou pronunciar palavras com sentido, ela passaria por um período de maturação em que, por meio dos outros sentidos, da capacidade de observação, concentração e imitação, com a ajuda do professor, seria capaz de articular palavras simples e significativas.

É necessário salientar que, a partir de 1930, a vertente psicopedagógica teve forte influência na educação das pessoas com deficiência. Sobre isso, Jannuzzi (2004, p. 130) confirma que a educação sensorial e a "concentração dos diversos ramos do ensino em torno dos interesses das crianças” são princípios da educação proposta pela pedagoga Helena Antipoff' no ensino dos alunos com deficiência e que se alinhavam com os princípios da Escola Nova. Nessa direção, podemos inferir que a desvalorização do ensino de matérias específicas para as crianças surdas também pode estar ligada a esse fato.

Comparando o currículo da escola primária regular com o currículo da escola especializada, Ana Rímoli disse que, se, na escola comum, as matérias eram apresentadas por meio de atividades e experiência, mais ainda na escola especializada deveriam receber um tratamento "objetivo e enérgico", fundamentado nos princípios da repetição e da objetivação. Para isso, seria fundamental um planejamento cuidadoso desse trabalho, já que a criança surda, ao contrário da criança ouvinte, se desenvolve com mais lentidão. A criança surda, em sua opiniâo, teria de percorrer outro caminho porque precisaria, em antes de tudo, "aprender a falar e, comparativamente com outras crianças, será lenta na aquisição dessa forma de comportamento” (Dória, 1959).

Em sua perspectiva, essa "deficiência” era a causa natural da desvantagem que sempre acompanhará o discurso sobre a criança surda. Esse pressuposto balizou o ensino adaptado ou reduzido, a necessidade de mais tempo na rotina escolar e uma educação especial. Na ocasião, a título de exemplo, apresentou o horário praticado na escola primária do instituto, conforme traz o Quadro 2:7

\footnotetext{
${ }^{6}$ Helena Antipoff, psicóloga e pedagoga russa, foi convidada, em 1929, por Francisco Campos, secretário de Educação de Minas Gerais, para integrar o grupo de profissionais da Escola de Aperfeiçoamento de Minas Gerais, fruto da Reforma do Ensino Primário, do governo mineiro, por meio do Decreto-lei no 7.970, de 15 de dezembro de 1927. Estudiosa da educaçáa do deficiente, foi responsável pela criaçáo da primeira Sociedade Pestalozzi no Brasil.

7 “Cursos regulares para surdos - 1) Pré-primário - Feita em três anos para crianças de 5 a 7 anos de idade, sendo as crianças distribuídas atendendo às exigências pedagógicas modernas (com brinquedos tipo parque) em 2 turnos. O campo de socialização é amplo, quanto possível, com grande número de passeios e festividades. Particularmente marcante nesse setor é a existência de uma banda rítmica, cuja primordial finalidade é auxiliar os deficientes, quanto ao problema do ritmo, cuja importância assume elevadas proporçôes na complementação da educaçâo que é, às crianças, ministrada. 2) Primário - No terreno da educação primária, as crianças de idade compreendida entre 8 e 13 anos, são ensinadas durante 6 anos, incluindo o seu currículo (nos dois últimos anos) a orientação pré-vocacional, funcionando em regime integral para os alunos. Como método de ensino o INES adota, obrigatoriamente, o método oral puro" (Portaria no 19, de 20 de março de 1959, p. 3).
} 


\section{Matutino $-7 \mathrm{~h}$ às $11 \mathrm{~h}$}

7h30min - Entrada, chamada e inspeção

$8 \mathrm{~h}$ - Treinamento da compreensão da fala

8h20min - Mecânica da fala

8 h50min - Preparação para o recreio

9h - Recreio

9h30min - Treinamento audiovisual

10h- Matemática

10h50min - Preparação para o almoço

Almoço - Descanso

\section{Vespertino $-13 \mathrm{~h} 30 \mathrm{~min}$ às $17 \mathrm{~h}$}

13h30min - Entrada e acomodação

13h45min - Linguagem oral e escrita (com conhecimentos gerais): a) leitura, b) cópia, c) caligrafia, d) ditado

$14 \mathrm{~h} 45 \mathrm{~min}$ - Preparação para o lanche

15h30min - Continuação da linguagem oral e escrita com treinamento audiovisual

16h - Desenho ou trabalhos manuais

16h30min - Atividades livres e preparação para o jantar

Arrumação e asseio da sala

$17 \mathrm{~h}$ - Jantar

Quadro 2. Horário das aulas no Imperial Instituto de Surdos-Mudos

Fonte: Adaptado pelos autores do acervo do INES.

A Matemática e os conhecimentos gerais ocupam um espaço insignificante, se comparados às atividades com linguagem oral, confirmando que esse era o conhecimento privilegiado nos processos de ensino-aprendizagem no início da alfabetizaçáo. Com relação a esse aspecto - o ensino da linguagem oral -, acreditamos que Vygotski (1997) nos ajuda a compreender a preocupação de Ana Rímoli com esse aprendizado. De acordo com esse autor, a surdez, vista exclusivamente como uma deficiência orgânica, não seria grave, pois não produz atrasos no desenvolvimento geral da criança, porém a ausência de fala decorrente da surdez ou a impossibilidade de dominar a linguagem "engendram uma das complicaçóes mais penosas de todo o desenvolvimento cultural” (Vygotski, 1997, p. 27), ou seja, acarretam problemas para o desenvolvimento cultural e biológico das crianças.

De certo modo, esse autor confiava nas tecnologias criadas para proporcionar o desenvolvimento cultural das crianças deficientes. No caso das crianças surdas, menciona uma fala mímico-gestual que, no momento, ainda não era pensada no Brasil para solucionar o problema da linguagem, pois ensinar a falar seria o caminho mais penoso para as crianças surdas.

Outro aspecto abordado na palestra refere-se à classificação dos alunos para a formação das classes homogêneas. Segundo Mortatti (2006), com o lançamento do livro Testes ABC para verificação da maturidade necessária ao aprendizado da leitura e da escrita, em 1934, de M. B. Lourenço Filho, os Testes de Inteligência começaram a ser aplicados nas classes de alfabetização no Brasil, "como forma de medir o nível de maturidade necessária ao aprendizado da leitura e escrita, a fim de classificar os alfabetizandos, visando à organização de classes homogêneas e à racionalização e eficácia da alfabetização" (Mortatti, 2006, p. 9). 
No contexto da Educação Especial, Jannuzzi (2004) afirmou que essa prática foi amplamente utilizada na década de 1930 para classificar e separar as crianças que não acompanhavam os conteúdos escolares como a maioria dos colegas das classes regulares, pois a definição de inteligência estava atrelada ao desempenho escolar. $\mathrm{O}$ teste servia para diagnosticar as dificuldades e confirmar a anormalidade das crianças. Seguindo a classificação do Teste de Inteligência, desenvolvido por Binet, as crianças eram separadas em classes especiais. No discurso de Ana Rímoli, não vemos uma indicação clara dos Testes de Inteligência utilizados; contudo, ela afirma que

o agrupamento em uma mesma classe, de elementos mais capazes de mais rápida assimilação (seja devido ao nível de inteligência mais elevado, seja devido aos resíduos considerados de audição) com outros menos capazes, de assimilação mais lenta (por possuir um Q.I. mais baixo ou por serem profundamente surdos) impossibilitando a homogeneidade da classe, redundará [...] em prejuízo de rendimento do ensino, já que está na razão direta daquela. (Dória, 1959).

Então, observamos que, entre as crianças surdas, existiam formas de classificação que tentavam diferenciá-las: por critérios biológicos, a partir do grau de perda auditiva (parcial ou profunda), considerando se a surdez aconteceu antes ou depois da aquisição da linguagem, a forma ou o modo de ocorrência da surdez (gradativa ou súbita) e a idade cronológica; por critérios cognitivos, como o nível de inteligência; por critérios psicológicos, como o equilíbrio emocional e a personalidade; e por critérios sociais, como o ambiente, seja no lar, seja na escola.

Ana Rímoli concluiu sua tese, em direção ao modelo ideal na educação de crianças surdas, afirmando que, somada a todos esses requisitos, está "a aptidão do professor para a carreira e o seu devido preparo específico - fator que interfere no rendimento - como é fácil de verificar” (Dória, 1958).

\section{Consideraçóes finais}

À vista do que conhecemos sobre a história da educação de surdos, sabemos que o oralismo, como método pedagógico, foi adotado amplamente no Instituto, já que o cientificismo respaldava a relação entre Medicina e Educação, validando as pesquisas que tinham como foco a cura das anormalidades ou deficiências. Com a posse de Ana Rímoli de Faria Dória como diretora do Instituto, uma mudança significativa deu o tom do novo governo que ora se estabelecia: o Instituto Nacional de Surdos-Mudos passa a se chamar Instituto Nacional de Educação de Surdos, confirmando que o termo mudo já não se aplicava ao novo modelo educacional em direção à oralização.

Nesse contexto, são incorporadas no currículo da formação de docentes disciplinas ligadas à correção da deficiência auditiva, com o objetivo de capacitar os professores para esse árduo trabalho, ou seja, "ensinar" o surdo a falar. Por outro lado, também encontramos vestígios de que, além da influência da Medicina e da Psicologia nos discursos sobre a educação de surdos, houve um amplo diálogo com as perspectivas teóricas, ligadas ao campo da alfabetização, no que diz respeito a métodos de alfabetização e material didático. Com base nos métodos que tinham por finalidade ensinar a linguagem oral, os documentos evidenciam as marcas do trabalho escolar, em diálogo direto com as concepçóes da época, fazendo-nos refutar o discurso 
hegemônico de que, nesse período, os estudantes surdos foram circunscritos em uma visão puramente clínica e terapêutica.

Podemos concluir que a educação de surdos no Brasil não se constituiu à revelia das enunciações que lhe foram contemporâneas. Ao contrário, os discursos produzidos pelos sujeitos mostram um projeto que, ao longo do tempo, dialogou com concepçóes anteriores, produziu novos conceitos, enfim, criou um movimento descontínuo e complexo. Acreditamos que os documentos mobilizados nos fizeram ver uma concepção de educação calcada na correção por meio do ensino da fala.

É necessário salientar, conforme assinala Rocha (2009), que a presença de Ana Rímoli, primeira mulher que dirigiu o INES, destacou-se, principalmente, pelos investimentos feitos em torno da educação das crianças surdas, não somente em termos de atuação profissional, mas também pelas obras publicadas sobre esse tema e pela criação de um Curso Especializado para a Educação de Surdos. Neste artigo, salientamos a formação de professores e o método adotado, em busca de aprofundar e ampliar conhecimentos no campo da historiografia da educação de surdos.

Com relação a esses dois aspectos, podemos concluir que o INES, na gestão de Ana Rímoli de Faria Dória (1951 a 1961), em consonância com a política nacional-desenvolvimentista, buscou construir bases científicas para a formação e a educação de crianças surdas, sem perder de vista a finalidade remidora da educação e, portanto, missionária dos professores preparados para ensinar crianças.

Apesar das críticas que possamos fazer, na atualidade, ao movimento ocorrido nesse momento, é necessário salientarmos, como assinala Vygotski (1997), que a escola e seus métodos sempre foram pensados com base na existência de um intelecto e órgãos avaliados como normais e a partir de etapas que levam à construção de conhecimentos cada vez mais elaborados. Assim sendo, o fato de haver, dentre outros movimentos, uma forte preocupaçáo em adaptar a formação de professores e métodos de ensino à realidade e às condiçóes das crianças surdas parece-nos um avanço importante que, inclusive, contribuiu para romper com uma pedagogia hospitalar-medicamentosa (termo usado por Vygotski, 1997) não somente para as crianças surdas.

\section{REFERÊNCIAS}

Araújo, M. A. de. (1959). Da necessidade da criação de um órgão de supervisão e controle das atividades técnico-pedagógicas dos estabelecimentos de ensino emendativo no Brasil. Artigo apresentado na $1^{\text {a }}$ Conferência Nacional de Professores de Surdos, Rio de Janeiro, Brasil.

Bakhtin, M. (1992). Marxismo e filosofia de linguagem. Tradução de M. Lahud, \& Y. F. Vieira. São Paulo: Hucitec.

Bloch, M. (2001). Apologia da história ou o ofício do historiador. Rio de Janeiro: Jorge Zahar.

Cardoso, L. da L., \& Herold Júnior, C. (2016). Educação e surdez na década de 1950 no Brasil: um panorama histórico acerca de Ana Rímoli de Faria Dória. Revista HISTEDBR on-line, 68, 138156. DOI: https://doi.org/10.20396/rho.v16i68.8645139 
Dória, A. R. de F. (1958). Compêndio de educação da criança surdo-muda. Rio de Janeiro: Instituto Nacional de Educação de Surdos.

Dória, A. R. de F. (1959). O problema da preparação do professor especializado: aspectos psico-pedagógicos. Artigo apresentado na $1^{\text {a }}$ Conferência Nacional de Professores de Surdos, Rio de Janeiro, Brasil.

Dória, A. R. de F. (1961). Manual de educação da criança surda. Rio de Janeiro: Instituto Nacional de Educação de Surdos.

Fausto, B. (2010). História do Brasil. São Paulo: Editora Universidade de São Paulo.

Luckesi, C. (1994). Filosofia da educação. São Paulo: Cortez.

Mortatti, M. do R. L. (2006). História dos métodos de alfabetização no Brasil. Seminário Alfabetização e Letramento em Debate. Brasília. Recuperado em 2 de outubro de 2014 de http://portal.mec.gov. $\mathrm{br} / \mathrm{seb} /$ arquivos/pdf/Ensfund/alf_mortattihisttextalfbbr.pdf

Neves, G. V. (2011). Educação de surdos em Caxias do Sul de 1960 a 2010: uma história escrita a várias mãos (Dissertação de Mestrado). Centro de Filosofia e Educação, Universidade de Caxias do Sul, Caxias do Sul, Rio Grande do Sul, Brasil.

Portaria $n^{\circ}$ 19, de 20 de março de1959. Recuperado em 8 de janeiro de 2020 de http://www.in.gov.br/ materia/-/asset_publisher/Kujrw0TZC2Mb/content/id/7510592/do1-2018-03-22-portaria-n-19de-20-de-marco-de-2018-7510588

Rocha, S. M. da. (2009). Antíteses, diades, dicotomias no jogo entre memória e apagamento presentes nas narrativas da história da educação de surdos: um olhar para o Instituto Nacional de Educação de Surdos (1856/1961) (Tese de Doutorado). Centro de Teologia e Ciências Humanas, Pontífice Universidade Católica do Rio de Janeiro, Rio de Janeiro, Brasil.

Rocha, S. M. da. (2010). Memória e história: a indagação de Esmeralda. Rio de Janeiro: Editora Arara Azul.

Sapir, E. (1954). A linguagem, introdução ao ensino da fala. Rio de Janeiro: MEC.

Schmitt, D. (2008). Contextualização da trajetória dos surdos e educação de surdos em Santa Catarina. (Dissertação de Mestrado). Centro de Ciência da Educação, Universidade Federal de Santa Catarina, Florianópolis, Brasil.

Soares, M. A. L. (1996). O oralismo como método pedagógico: contribuição ao estudo da história da educação do surdo no Brasil (Doutorado em Educação). Faculdade de Educação, Universidade Estadual de Campinas, Campinas, São Paulo, Brasil.

Souza, V. dos R. M. (2007). Gênese da educação de surdos em Aracaju (Tese de Doutorado). Faculdade de Educação, Universidade Federal da Bahia, Salvador, Bahia, Brasil.

Svobodová, I. (2008). Estilística e a sua posição dentro do contexto da linguistica portuguesa. In Sborník prací filozofické fakulty Brněnské univerzity/Studia minora facultatis philosophicae universitatis brunensis. L 29, Brno, Rep. Checa. Recuperado em 25 setembro de 2019 de file://C:/Users/User/ Downloads/estilisticaeasuaposicaonalingusticaportuguesa.pdf

Teixeira, L. R., \& Mota, M. B. (2011). Edward Sapir e Mattoso Câmara Jr.: intersecçóes. Working paper em Linguistica, 12(2), 15-34. DOI: https://doi.org/10.5007/1984-8420.2011v12n2p15

Vygotski, L. S. (1997). Obras escogidas V: fundamentos de defectologia. Madrid: Visor.

Recebido em: 01//08/2019

Reformulado em: 25/10/2019

Aprovado em: 03/11/2019 